\title{
A Case Study of Transitivity Analysis of Trump's Winning Speech Based on Systematic Functional Grammar
}

\author{
Li Jing, Li Fengjie*
}

Foreign Languages Department, Tianjin University of Finance and Economics, Tianjin, China

\author{
Email address: \\ yyfx0901@163.com (Li Fengjie) \\ *Corresponding author
}

\section{To cite this article:}

Li Jing, Li Fengjie. A Case Study of Transitivity Analysis of Trump's Winning Speech Based on Systematic Functional Grammar. International Journal of Language and Linguistics. Vol. 7, No. 4, 2019, pp. 150-157. doi: 10.11648/j.jill.20190704.12

Received: April 2, 2019; Accepted: May 23, 2019; Published: July 2, 2019

\begin{abstract}
The systematic functional grammar proposed by Halliday has profound influence on the linguistic theory research in the second half of the 20th century. Halliday believes language has three meta-functions: ideational function, interpersonal function and textual function. The ideational function is to convey new information, to communicate a content that is unknown to the hearer. The ideational function mainly consists of transitivity and voice. Transitivity is simply the grammar of the clause in its ideational aspect. It consists of six different processes: Material process, Behavioral process, Mental process, Verbal process, Relational process and Existential process. Political speech is an important form of public speech and it plays an extremely important role in political life. Based on Halliday's ideational functional theory, the thesis selects Trump's winning speech and analyzes it from the perspective of transitivity system. The main purpose of the article is to analyze Trump's language skills, and at the same time, provide a research idea and method for readers to interpret political speech discourse. This article revolves around the following two questions: 1. How are the six processes distributed in Trump's winning speech? 2. What are the functions of the six processes in Trump's speech? Based on these two questions, this paper conducts statistics on speech through quantitative and qualitative analysis. Through analysis, the author finds that there are three processes used frequently. They are relational process $(35 \%)$, material process $(30 \%)$, mental process $(24 \%)$ in turn. While the verbal process $(8 \%)$, the behavioral process $(2 \%)$, and the existential process $(1 \%)$ are very low frequency. This is because of Trump's speech intention. As a new president, he needs to express his own ideas, clarify his position and policies affecting people's emotions, call for public support, and clarify his vision and plan for the future of the United States.
\end{abstract}

Keywords: Ideational Function, Transitivity, Trump's Winning Speech

\section{Introduction}

Halliday is the leader of the systemic functional grammar, which has great inspiration for linguists. He believes that language mainly has three meta-functions: ideational function, interpersonal function and textual function. Ideational function is to convey new information, to communicate a content that is unknown to the hearer. The ideational function includes the experimental function and logical functions, and the experimental function includes the transitive system and the voice system. Halliday believes that experimental function is realized by transitive system, which is composed of material processes, mental processes, relational processes, behavioral processes, verbal processes, and existential processes [1].
Political speech is an important form of public speech and it plays an extremely important role in political life. There are many researches on political speech. Most of the domestic studies about political speech are studied from the perspective of interpersonal function and textual function, there is almost no research from the perspective of ideational function. In this paper, the author analyzes Trump's winning speech from the perspective of transitivity, in order to understand the purpose of transitivity and the political intentions behind the speech. Although there were some scholars have studied Trump's speeches, they just analyzed them roughly and merely focused on the impact of his victory on the world. So it is necessary to study Trump's winning speech from the perspective of transitivity.

The paper is divided into five parts. The first part is 
introduction, which mainly introduces the research purpose, research significance and the structure of this paper. The literature review mainly talks about previous studies at home and abroad, providing related knowledge of the topic. Then the theoretical framework, this part introduces meta-functions in detail. Finally the conclusion, in this part, the author makes a summary and gives major findings and the paper's limitations.

\section{Literature Review}

At home and abroad, the study of systemic functional linguistics is very extensive. From the systemic functional linguistic theories to the development of systemic functional linguistics, many scholars have made important contributions, such as Halliday, Thompson and Butt. Systemic functional linguistics is also used to analyze various texts, and systemic functional linguistics opens up a new way of text analysis. Many scholars in China have played an important role in the introduction of systemic functional linguistics into China and enriched the theory of systemic functional linguistics, such as $\mathrm{Hu}$ Zhuanglin, Wang Zongyan and Zhang Delu. There are also many scholars in China who systemic functional grammar to analyze the literature, public speech, film and advertisement etc.

Political speech is an important form of public speech and plays an extremely important role in its political life. The study of political speech is also very hot, and has always been the main source of corpus for linguists at home and abroad. Political speech has three major characteristics: the political nature of the topic, the agitation of the content and the rigorous logic [2]. Speakers should show their political inclinations, publicize their own political views, and strive to correctly grasp the correct direction of history. Such speeches serve a certain political purpose [3]. Through speeches, the audience can understand their own political platforms or political views, thus gaining understanding and support. This is the most basic purpose of speech.

\subsection{Previous Studies About SFG at Aboard}

The founder of systemic functional linguistics is Halliday, who inherited and developed theories of predecessors. Halliday is a major member of the London School. His academic thoughts were deeply influenced by Firth and Malinowski. He believes that language mainly has three meta-functions: ideational function, interpersonal function and textual function [4]. In the article Notes on Transitivity and Theme in English, Halliday elaborated on the main points of ideational function and transitivity system [5]. In foreign countries, many scholars have studied the systemic functional grammar from different fields. For example, Halliday first analyzed William Golding's The Inheritors by using this theory. Since then, other scholars continued to study the SFG. Kennedy analyzed The Secret Agent and Two Gallants from interpersonal function in 1982 [6]. And the Functional English grammar: An Introduction to the Second Language Teachers written by Lock, mainly to make important suggestions on the teaching method [7]. The Functional Analysis of English: A Hallidayan Approach written by Bloor. In the book, Bloor believes that the teaching process should pay attention to the thematic progression and systemic functional grammar plays an increasingly prominent role in teaching [8].

\subsection{Previous Studies About SFG at Home}

In China, the introduction of systemic functional linguistics was introduced in the early 1980s, systemic functional linguistics provided advice to Chinese scholars on teaching methods and played a positive role in the reform of Chinese foreign language teaching. Wang Zongyan first introduced some theoretical views of the London School in Language Theory of the London School Founder, he introduced Halliday's linguistic achievements, and introduced functional linguistic theories into China [9]. Hu Zhuanglin systematically introduced Halliday's functional theory and pointed out that systemic functional grammar plays an important role in modern foreign language teaching and discourse analysis [10].

In recent years, there are many scholars in China who systemic functional grammar to analyze the literature, public speech , film and advertisement etc. Sun Jihong analyzes two articles about foot pain from the perspective of transitivity, tries to find out the different transitivity chosen by the authors according to their different purposes, and further explores how transitivity help them achieve their goals [11]. Zhang Yuexian analyzes the classic novel Machi's Gift by using the theory of transitivity in systemic functional linguistics, and examines the distribution of six types of process types in the text, and analyzes the four types of process used mainly by examples [12]. Zou Xiangxi compared the different expressions of English and Chinese in the analysis of the original text and four English versions of Chun Wang, and tried to translate the poem from the perspective of transitivity and finally she finds transitivity is instructive to achieve the medium-value effect of English-Chinese translation [13]. Liu Xuewei takes the transitive system in the systemic functional grammar as the theoretical framework, and uses Obama's speech at the 2014 West Point Military Academy Graduation Ceremony as a corpus to analyze the six processes of the discourse system in the discourse, aiming to better grasp the characteristics of the discourse and the intent of the speaker [14].

In summary, systemic functional grammar plays a role in many fields. Using systemic functional linguistic theory to analyze various subjects can make the analysis of texts more comprehensive, and the application fields of systemic functional linguistics will become more and more extensive. This article uses the ideational functional to analyze English political speech texts.

\section{Theoretical Framework}

Halliday proposes a theory of metafunctions of language, that is, language has ideational, interpersonal and textual functions [15]. Ideational function constructs a model of experience as well as logical relations, interpersonal function enacts social relationships and textual function creates 
relevance to context.

The ideational function mainly consists of transitivity and voice [16]. This function not only specifies the available options in meaning but also determines the nature of their structural realizations. Transitivity is composed of material processes, mental processes, relational processes, behavioral processes, verbal processes, and existential processes.

\subsection{Material Process}

Material process are clauses of doing-\&-happening: a material clause construes a quantum of change in the flow of events as taking place through some input of energy. [15] Material process are expressed by an action verb (beat, break, kick, etc), and Actor (logical subject) and the Goal of action (logical direct object, usually a noun or a pronoun). For example, "Mike opened the door", in this sentence, there are two participants: the Actor Mike and the Goal door.

Table 1. Material process.

\begin{tabular}{lll}
\hline Actor & Process: Material & Goal \\
\hline Mike & opened & the door \\
My mother & swept & the floor \\
The boy & jumped & \\
\hline
\end{tabular}

In a material clause, there is always one participant - the Actor. This participant brings about the unfolding of the process through time, leading to an outcome that is different from the initial phase of the unfolding. This outcome may be confined to the Actor itself, in which case there is only one participant inherent in the process. Such a material clause represents a happening, we can call it intransitive. Alternatively, the unfolding of the process may extend to another participant, the Goal, impacting it in some way: the outcome is registered on the Goal in the first instance, rather than on the Actor. Such a material clause represents a doing and we can call it transitive.

The nature of the outcome affecting the Actor of an intransitive clause and the Goal of a transitive one turns out to be the general criterion for recognizing more delicate sub-types of material clauses. The most general contrast is between (1) creative clauses, where the Actor or Goal is construed as being brought into existence as the process unfolds, and (2) transformative ones, where a pre-existing Actor or Goal is construed as being transformed as the process unfolds. The transformative type of material clause covers a much wider range than the creative type. The outcome of the transformation is an (1) elaboration, (2) extension or (3) enhancement of the Actor (intransitive) or Goal (transitive).

Table 2. Examples of verbs serving as Process in different material clause types.

\begin{tabular}{|c|c|c|c|}
\hline & & Intransitive & Transitive \\
\hline \multirow[t]{2}{*}{ creative } & general & $\begin{array}{l}\text { appear, emerge, occur, etc } \\
\text { develop, form, grow, produce }\end{array}$ & \\
\hline & & & create, make, prepare \\
\hline \multirow{3}{*}{ transformative } & $\begin{array}{l}\text { specific } \\
\text { elaborating }\end{array}$ & $\begin{array}{l}\text { erupt, boom, blush, pale, etc } \\
\text { break, burst, toll, ring, etc }\end{array}$ & $\begin{array}{l}\text { assemble, build, construct, open, establish, etc } \\
\text { crush, destroy, mash, etc }\end{array}$ \\
\hline & extending & $\begin{array}{l}\text { hire, rent, sell, etc } \\
\text { join, meet, spread, etc }\end{array}$ & give, feed, rob, etc \\
\hline & enhancing & $\begin{array}{l}\text { go, come, return, etc } \\
\text { jump, fly, run, etc }\end{array}$ & bring, take \\
\hline
\end{tabular}

\subsection{Mental Process}

Mental clauses are concerned with our experience of the world of our own consciousness. They are clauses of sensing: a mental clause construes a quantum of change in the flow of events taking place in our own consciousness. This process of sensing may be construed either as flowing from a person's consciousness or as impinging on it; but is not construed as a material act. Mental processes express such mental phenomena as "perception" (see, look), "reaction" (like, please) and "cognition" (know, believe, convince). A mental process involves two participants: Senser and Phenomenon. For example, "I didn't like the sugar", in this sentence, "I" is Senser, "the sugar" is Phenomenon, "didn't like" is a emotive verb.

Within the general class of 'mental' clauses, there are four different sub-types of sensing: perceptive, cognitive, desiderative and emotive.

e.g (a) He likes the car. (emotive) (b) He wants the car. (desiderative)

(c) He knows the car. (cognitive)

(d) He saw the car.(perceptive)

Table 3. Mental process

\begin{tabular}{lll}
\hline Senser & Process: Mental & Phenomenon \\
\hline I & like & her \\
The new & shocked & her \\
She & watched & the movie \\
$\mathrm{He}$ & know & What I meant \\
\hline
\end{tabular}

\subsection{Relational Process}

Relational clauses serve to characterize and to identify. The English system operates with three main types of relation 'intensive', 'possessive' and 'circumstantial'; and each of these comes in two distinct modes of being - 'attributive' and 'identifying'. 
Table 4. Relational process.

\begin{tabular}{|c|c|c|}
\hline & attributive & identifying \\
\hline intensive & $\mathrm{He}$ is smart & $\begin{array}{l}\text { Tom is the leader } \\
\text { The leader is Tom }\end{array}$ \\
\hline possessive & Mary has a cat & $\begin{array}{l}\text { The cat is Mary's } \\
\text { Mary's is the cat }\end{array}$ \\
\hline circumstantial & The fair is on Tuesday & $\begin{array}{l}\text { Tomorrow is the } 10^{\text {th }} \\
\text { The } 10^{\text {th }} \text { is tomorow }\end{array}$ \\
\hline
\end{tabular}

\subsection{Verbal Process}

Verbal process is the process of exchanging information through speech. Verbs usually are 'say', 'tell', 'talk', 'praise', etc. Participants typically include 'sayer', 'receiver', 'verbiage'.

Table 5. Verbal process.

\begin{tabular}{lllll}
\hline sayer & Process: verbal & target & receiver & verbiage \\
\hline The teacher & repeated & & & the question \\
My mother & praise & me & to my brother & \\
& Tell & me & & your secret \\
\hline
\end{tabular}

\subsection{Behavioural Process}

These are processes of (typically human) physiological and psychological behaviour, like breathing, coughing, smiling, dreaming and staring. They are the least distinct of all the six process types because they have no clearly defined characteristics of their own; rather, they are partly like the material and partly like the mental. Generally only one participant, Behaver, often a human, is involved in this kind of processes."

Table 6. Behavioural process.

\begin{tabular}{ll}
\hline Behaver & Process:behavioural \\
\hline $\mathrm{He}$ & cried \\
\hline
\end{tabular}

\subsection{Existential Process}

Existential processes represent that something exists or happens. In every existential process, there is an Existent.

Table 7. Existential process.

\begin{tabular}{llll}
\hline & Process:existential & existent & circumstance \\
\hline There & is & a book & on the table \\
\hline
\end{tabular}

\section{Transitivity Analysis of Trump's Winning Speech}

Transitivity is simply the grammar of the clause in its ideational aspect. It consists of six different processes: Material process, Mental process, Relational process, Verbal process, Behavioral process, Existential process. In this paper, the author will analyze the speech from six processes of transitivity. And the results as follows:

Table 8. Transitivity analysis of Trump's winning speech.

\begin{tabular}{|c|c|c|c|c|c|c|c|}
\hline Speech process & material & mental & relational & verbal & behavioral & existential & total \\
\hline \multirow{2}{*}{ Trump's winning speech } & 80 & 65 & 96 & 23 & 6 & 4 & 274 \\
\hline & $30 \%$ & $24 \%$ & $35 \%$ & $8 \%$ & $2 \%$ & $1 \%$ & $100 \%$ \\
\hline
\end{tabular}

The above table shows that there are three processes used frequently. They are relational process, material process, mental process in turn, which occur 96 times, 80 times and 65 times, respectively, accounting for $35 \%, 30 \%$ and $24 \%$ of the total. While the verbal process, the behavioral process, and the existential process are very low frequency. Next, we will analyze them in detail.

\subsection{Analysis of Material Process}

Material process refer to physical actions. Material process are expressed by an action verb (beat, break, kick, etc), and Actor (logical subject) and the Goal of action (logical direct object, usually a noun or a pronoun). Political speech has certain objectivity, so in political speeches, the speaker describes the current situation and the current political and economic situation by using material process to describe the measures to be taken in the future. In addition, political speeches serve a certain political purpose. So in speeches, the speaker usually uses action words to arouse listener's interest and so the audience can understand their political views.

Material processes are used frequently in Trump's winning speech, in the speech, Trump uses dynamic words to describes the current situation and the current political and economic situation. He focuses on rebuilding infrastructure and caring for the people. For example:
(1) I congratulated her and her family on a very, very hard-fought campaign.

(2) We owe her a major debt of gratitude for her service to our country

From above examples, Trump conveyed to the people that he shared the same thanks to the people for Hillary's contribution to the country, and he will lead the American people to a new journey.

(3) We are going to fix our inner cities and rebuild our highways, bridges, tunnels, airports, schools, hospitals. We're going to rebuild our infrastructure, which will become, by the way, second to none, and we will put millions of our people to work as we rebuild it.

(4) We will embark upon a project of national growth and renewal. I will harness the creative talents of our people.

(5) We're going to get to work immediately for the American people and we're going to be doing a job that hopefully you will be so proud of your president.

Above examples show that Trump will take concrete measures to develop the US economy, reflecting his determination and ambition to change the status and making his speech more credible and persuasive.

Now it is time for America to bind the wounds of division, have to get together.

In this example, Trump use 'bind' and 'get together' stress 
people should be united, so people have motivation to rebuild the country.

\subsection{Analysis of Mental Process}

Mental process are those of thinking, imagining, liking, sensing, wanting, seeing, hearing-something that goes on in the internal world of the mind. A mental process involves two participants: Senser and Phenomenon. The use of a large number of mental processes in the speech helped Trump to create an intimate and emotional atmosphere, which greatly narrows the distance between him and the audience. In the mental process, the vast majority are expressions of positive emotions, which make the American people feel pleasant and comfortable. It reflects the positive and sincere attitude of the new president, establishes a positive social image, and also encourages the morale of the American people. And in the speech, the word 'thank' is used frequently, it shows that his deep gratitude to his family, voters and the campaign team. For example:

(7) ... who I know are looking down on me right now. (cognitive)

(8) We expect to have great, great relationships. (cognitive)

(9) A very special person who, believe me... (cognitive)

(10) we appreciate them.. (cognitive)

The examples all belong to cognitive mental process, Trump used 'know', 'expect' 'believe', 'appreciate', example (7) (9) express Trump' thanks to his parent and his team, example (8) shows that Trump's deep desire for people's unifying, and example (10), Trump introduced a special person to audience.

That is now what I want to do for our country. (desiderative)

I pledge to every citizen of our land (desiderative)

The examples belong to desiderative mental process, in speeches, Trump often use 'want' to show his sincere commitment to the American people and he have a desire for rebuilding the country.

(13) I love you and I thank you. (emotive)

And verbs 'love', 'thank' belong to emotive mental process, which express his deep love and gratitude to the American people.

\subsection{Analysis of Relational Process}

The relationship process is used to express the relationship between things, reflecting people's interpretation of objective things and understanding of various relationships. The relational process ranks first in the speech, and through these relationships, on the one hand, he expressed the relationship with the campaign opponents, campaign teams, relatives, etc., expressed gratitude to them, and established an intimate relationship with the audience, shortening the distance with the audience, and making his political ideas more credible. For example:

No dream is too big, no challenge is too great. (attributive)

This was tough. This was tough. (attributive)

We have a great economic plan. (possessive)

Examples (14) (15) (16)belong to relational process, the former part and the latter part are linked with 'be'. The example (14) revels Trump's ambition to rebuild the United
States. The example (15) express the process of being the president is tough. And examples (16), Trump used 'have' to show the economic plan he will take and he encouraged people to believe that government will serve for people.

(17) Ours was not a campaign but rather an incredible and great movement. (identifying)

(18) Reince is a superstar. (identifying )

The above examples are identifying relational processes. Trump described the current status of the United States, the greatness of Americans and the excellence of his team to the audience through the relational process.

\subsection{Analysis of Verbal Process}

Verbal process are those of exchanging information. Commonly used verbs are say, tell, talk, describe, etc. In these processes the main participants are Sayer, Receiver, and Verbiage. In Trump's speech, verbal processes occur 23 times. By using verbal processes reflects the authority of the presidential status and can help the American people create a sense of responsibility and raise the awareness of national unity. And Trump mainly arouse the attention of the audience and ensure that Americans can unite together (eg 19). And he emphasize his political views, tell the world 'American first' and call on all people to act to rebuild the United States. (eg 21)

(19) I say it is time for us to come together as one united people.

(20) As I've said from the beginning...

(21) I want to tell the world community that while we will always put America's interests first.

\subsection{Analysis of Behavioral Process}

Behavioral process refer to physiological and psychological behavioral such as breathing, coughing, crying, etc. In Trump's speech, verbal processes occur only 6 times. For example:

(22) I've spent my entire life in business, looking at the untapped potential in projects and in people all over the world.

(23) Look at all of the people that we have. Look at all of these people.

Example (22) shows that Trump has confidence in rebuilding the United States and rebuilding the American dream because he saw the potential of the American people. Example (23) shows that Trump has the support of a huge team.

\subsection{Analysis of Existential Process}

Existential process represent that something exists or happens. A typical existential process is 'there be...', and which occurs 4 times in Trump's speech. The existential process is less used in political speeches, because excessive use of the existential process in the speech makes the speech tedious and difficult to attract the attention of the audience. However, the existential process expresses the objectivity of things, and the proper use of the existential process can enhance the objectivity of speech.

(24) It is going to happen. 
(25) We have over 200 generals and admirals that have endorsed our campaign and there are special people.

The above examples, Trump used the existential process to objectively analyze the domestic situation and show that they have a clear judgment on the current situation, thus making the speech more objective.

\section{Conclusion}

In this paper, the author analyzes Trump's winning speech from the perspective of transitivity, in order to understand the purpose of transitivity and the political intentions behind the speech. Through analysis, the author find that there are three processes used frequently. They are relational process (35\%), material process $(30 \%)$, mental process $(24 \%)$ in turn. While the verbal process $(8 \%)$, the behavioral process $(2 \%)$, and the existential process $(1 \%)$ are very low frequency. This is because of Trump's speech intention. Firstly, political speech has certain objectivity, so in political speeches, Trump describes the current situation and the current political and economic situation by using material process. Secondly, the use of a large number of mental processes in the speech helped Trump to create an intimate and emotional atmosphere, which greatly narrows the distance between him and the audience. Thirdly, Trump described the current status of the United States, the greatness of Americans and the excellence of his team to the audience through the relational process. Then by using verbal processes, he mainly arouse the attention of the audience and call on people.

Although the author tries her best to analyze the speech, there are some limitations. Firsty, Trump has had many speeches since he took office, so analyzing this speech alone is not enough to explore his political intentions. In addition, the paper just focus on transitivity system, but ideational function also includes voice system, which is not referred in the paper. So further studies can focus on ideational function comprehensively.

\section{Appendix}

material process (MA)

mental process $(\mathrm{ME})$

relational process $(\mathrm{RE})$

communicative process (COM)

behavioral process $(\mathrm{BE})$

existential process (EX)

Thank (emotive ME) you. Thank (emotive ME) you very much, everyone. Sorry (emotive ME) to keep (attributive RE) you waiting (MA). Complicated business, complicated. Thank (emotive ME) you very much.

I've just received (transitive MA) a call from secretary Clinton. She congratulated (transitive MA) us. It's (identifying RE) about us. On our victory, and I congratulated (transitive MA) her and her family on a very, very hard-fought campaign. I mean (RE) she fought (intentional MA) very hard. Hillary has worked (intentional MA) very long and very hard over a long period of time, and we owe (ME) her a major debt of gratitude for her service to our country. I mean (RE) that very sincerely.

Now it is (RE) time for America to bind (MA) the wounds of division, have to get (MA) together, to all Republicans and Democrats and independents across this nation I say (COM) it is (RE) time for us to come (MA) together as one united people.

It is (RE) time. I pledge (desiderative ME) to every citizen of our land that I will be (identifying RE) president for all of Americans, and this is (RE) so important to me. For those who have chosen (intentional MA) not to support (ME) me in the past, of which there were (EX) a few people, I'm reaching out (MA) to you for your guidance and your help so that we can work (intentional MA) together and unify (abstract MA) our great country. As I've said (COM) from the beginning, ours was (identifying RE) not a campaign but rather an incredible and great movement, made up of (RE) millions of hard-working men and women who love (emotive ME) their country and want (desiderative ME) a better, brighter future for themselves and for their family. It is (identifying RE) a movement comprised of (RE) Americans from all races, religions, backgrounds and beliefs, who want (desiderative $\mathrm{ME}$ ) and expect (cognitive ME) our government to serve (abstract MA) the people, and serve (MA) the people it will.

Working (abstract MA) together we will begin (abstract MA) the urgent task of rebuilding (creative MA) our nation and renewing (creative MA) the American dream. I've spent (abstract MA) my entire life in business, looking at (BE) the untapped potential in projects and in people all over the world.

That is (RE) now what I want (desiderative ME) to do (transitive MA) for our country. Tremendous potential. I've gotten to know (abstract MA) our country so well. Tremendous potential. It is (RE) going to be (RE) a beautiful thing. Every single American will have (possessive RE) the opportunity to realize (abstract MA) his or her fullest potential. The forgotten men and women of our country will be forgotten (cognitive ME) no longer.

We are going to fix (creative MA) our inner cities and rebuild (creative MA) our highways, bridges, tunnels, airports, schools, hospitals. We're going to rebuild (creative MA) our infrastructure, which will become (RE), by the way, second to none, and we will put (MA) millions of our people to work (specific MA) as we rebuild (creative MA) it. We will also finally take care of (transitive MA) our great veterans who have been (attributive RE) so loyal, and I've gotten to know (abstract MA) so many over this 18-month journey. The time I've spent (abstract MA) with them during this campaign has been (RE) among my greatest honors. Our veterans are (attributive RE) incredible people.

We will embark upon (creative MA) a project of national growth and renewal. I will harness (creative MA) the creative talents of our people and we will call upon (COM) the best and brightest to leverage their tremendous talent for the benefit of all. It is (RE) going to happen (EX). We have (possessive RE) a great economic plan. We will double (creative MA) our growth and have (RE) the strongest economy anywhere in the world. At the same time we will get along with (MA) all other 
nations, willing to (desiderative ME) get along with (MA) us. We will be (RE). We will have (possessive RE) great relationships. We expect (cognitive ME) to have (possessive $\mathrm{RE}$ ) great, great relationships. No dream is (attributive RE) too big, no challenge is (attributive RE) too great. Nothing we want (desiderative ME) for our future is (RE) beyond reach.

America will no longer settle (MA) for anything less than the best. We must reclaim (creative MA) our country's destiny and dream big and bold and daring. We have to do (creative MA) that. We're going to dream of (desiderative ME) things for our country, and beautiful things and successful things once again.

I want (desiderative $\mathrm{ME})$ to tell (COM) the world community that while we will always put (MA) America's interests first, we will deal (abstract MA) fairly with everyone, with everyone. All people and all other nations. We will seek (abstract MA) common ground, not hostility, partnership, not conflict. And now I would like to (desiderative ME) take (MA) this moment to thank (emotive ME) some of the people who really helped (MA) me with this, what they are calling (COM) tonight a very, very historic victory.

First I want (desiderative ME) to thank (emotive ME) my parents, who I know (cognitive ME) are looking down on (BE) me right now. Great people. I've learned (MA) so much from them. They were (attributive RE) wonderful in every regard. They are (attributive RE) truly great parents.

I also want (desiderative ME) to thank (emotive ME) my sisters, Marianne and Elizabeth who are (circumstantial RE) here with us tonight. And where here are (circumstantial RE) they? They're (circumstantial RE) here someplace. They're (attributive RE) very shy actually. And my brother Robert, my great friend. Where is (circumstantial RE) Robert? Where is (circumstantial RE) Robert? My brother Robert, and they should be (circumstantial RE) on this stage but that's (attributive RE) okay. They're (attributive RE) great. And also my late brother Fred, great guy. Fantastic guy. Fantastic family. I was (attributive RE) very lucky. Great brothers, sisters, great, unbelievable parents. To Melania and Don and Ivanka and Eric and Tiffany and Barron, I love (emotive ME) you and I thank (emotive ME) you, and especially for putting up with (emotive ME) all of those hours. This was (attributive RE) tough. This was (attributive RE) tough. This political stuff is (attributive RE) nasty and it is (attributive RE) tough. So I want (desiderative ME) to thank (emotive ME) my family very much. Really fantastic. Thank (emotive ME) you all. Thank (ME) you all. Lara, unbelievable job. Unbelievable. Vanessa, thank (emotive ME) you. Thank (emotive ME) you very much. What a great group. You've all given (MA) me such incredible support, and I will tell (COM) you that we have (possessive RE) a large group of people. You know (cognitive ME), they kept saying (COM) we have (possessive RE) a small staff. Not so small. Look (BE) at all of the people that we have (RE). Look (BE) at all of these people. And Kellyanne and Chris and Rudy and Steve and David. We have got (MA), we have got (MA) tremendously talented people up here, and I want (desiderative ME) to tell (COM) you it's been (RE), it's been (attributive RE) very, very special.
I want (desiderative ME) to give (MA) a very special thanks to our former mayor, Rudy Giuliani. He's (attributive RE) unbelievable. Unbelievable. He traveled (intransitive MA) with us and he went through (MA) meetings, and Rudy never changes (MA). Where is (circumstantial RE) Rudy. Where is (circumstantial RE) he?

Gov. Chris Christie, folks, was (attributive RE) unbelievable. Thank (emotive ME) you, Chris. The first man, first senator, first major, major politician — let me tell (COM) you, he is highly respected (ME) in Washington because he is (attributive RE) as smart as you get, senator Jeff sessions. Where is (circumstantial RE) Jeff? A great man. Another great man, very tough competitor. He was (attributive RE) not easy. He was (attributive RE) not easy. Who is (RE) that? Is that the mayor that showed up (MA)? Is that Rudy? Up here. Another good friend . Really a friend to me, but I'll tell (COM) you, I got to know (MA) him as a competitor because he was (identifying RE) one of the folks that was negotiating (MA) to go against (ME) those Democrats, Dr. Ben Carson. Where's (circumstantial RE) Ben? Where is (circumstantial RE) Ben? By the way, Mike Huckabee is (circumstantial RE) here someplace, and he is (attributive RE) fantastic. Mike and his familiar bring (MA) Sarah, thank (ME) you very much. Gen. Mike Flynn. Where is (circumstantial RE) Mike? And Gen. Kellogg. We have (possessive RE) over 200 generals and admirals that have endorsed (ME) our campaign and there are (EX) special people. We have (possessive RE) 22 congressional medal of honor people.

A very special person who, believe (cognitive ME) me, Iread reports (COM) that I wasn't getting along with (MA) him. I never had (RE) a bad second with him. He's (identifying $\mathrm{RE}$ ) an unbelievable star. He is -- that's (RE) right, how did you possibly guess (cognitive $\mathrm{ME})$ ? Let me tell (COM) you about Reince. I've said (COM) Reince. I know (cognitive ME) it. I know (cognitive ME) it. Look at (BE) all of those people over there. I know (cognitive ME) it, Reince is (identifying RE) a superstar. But I said (COM), they can't call (RE) you a superstar, Reince, unless we win (transitive MA) it. Like secretariat. He would not have (RE) that bust at the track at Belmont. Reince is (identifying RE) really a star and he is (RE) the hardest working guy and in a certain way I did (MA) this. Reince, come up (MA) here. Get over (MA) here, Reince.

Boy, oh, boy, oh, boy. It's (RE) about time you did (MA) this right. My god. Nah, come (MA) here. Say (COM) something.

[Reince Priebus: Ladies and gentlemen, the next president of the united States, Donald Trump! Thank (ME) you. It's been (RE) an honor. God bless (ME). Thank (ME) God.]

Amazing guy. Our partnership with the RNC was (RE) so important to the success and what we've done (intentional MA), so I also have to say (COM), I've gotten to know (MA) some incredible people.

The Secret Service people. They're (attributive RE) tough and they're (attributive RE) smart and they're (attributive RE) sharp and I don't want (desiderative ME) to mess around with (MA) them, I can tell (COM) you. And when I want (desiderative ME) to go (intentional MA) and wave (specific 
MA) to a big group of people and they rip (specific MA) me down and put (MA) me back down in the seat, but they are (attributive RE) fantastic people so I want (desiderative ME) to thank (emotive ME) the Secret Service.

And law enforcement in New York City, they're (circumstantial RE) here tonight. These are (attributive RE) spectacular people, sometimes under appreciated unfortunately, we appreciate (cognitive ME) them. So it's been (RE) what they call (COM) an historic event, but to be (RE) really historic, we have to do (MA) a great job and I promise (desiderative ME) you that I will not let you down (ME). We will do (MA) a great job. We will do (MA) a great job. I look very much forward to (cognitive ME) being (identifying RE) your president and hopefully at the end of two years or three years or four years or maybe even eight years you will say (COM) so many of you worked (MA) so hard for us, you will say (COM) that - you will say (COM) that - that was (RE) something that you were (RE) - really were - very proud to do (MA) and I can — thank (ME) you very much - and I can only say (COM) that while the campaign is (RE) over, our work on this movement is (RE) now really just beginning (MA). We're going to get to work (MA) immediately for the American people and we're going to be doing (MA) a job that hopefully you will be so proud of (ME) your president. You will be so proud. Again, it's (RE) my honor.

It's (RE) an amazing evening. It's been (RE) an amazing two-year period and I love (emotive ME) this country. Thank (ME) you. Thank (ME) you very much. Thank (ME) you to Mike Pence.

\section{References}

[1] Halliday. M. A. K. An introduction to functional Grammar [M]. London: Edward Arnold, 1994.

[2] Devito, J. A. Elements of Public Speaking [M]. New York: Harper and Row, 1987.
[3] Diana Carlin. Public Speech [M]. Victoria: Deakin University Press, 1995.

[4] Halliday. M. A. K. An introduction to functional grammar [M]. Beijing: Foreign Language Teaching and Research Press, 2000.

[5] Huang Guowen. A review of systemic functional linguistics in China for 20 years $[\mathrm{J}]$. Foreign languages and their teaching, $2000(5)$

[6] Hu Zhuanglin. Introduction to Systemic Functional Linguistics [M]. Bei Jing: Peking University Press, 2008.

[7] Graham Lock. Functional English grammar: An Introduction to the Second Language Teachers [M]. Hong Kong: City University of Hong Kong, 2017.

[8] Thomas Bloor. The Functional Analysis of English: A Hallidayan Approach [M]. London: Edward Arnold, 2013.

[9] Ma Hui. Stylistic Study of the Speeches of Presidents of the United States and Russia--Taking Obama and Putin's Speech as an Example [D]. Heilongjiang University, 2016.

[10] Hu Zhuanglin. Linguistics and Chinese Foreign Language Teaching for 40 Years [J]. Foreign language teaching and research, 2018 (11)

[11] Sun Jihong. Functional grammar: transitivity analysis [J]. Education and Teaching Forum, 2018 (48)

[12] Zhang Yuexian. Using the theory of transitivity to analyze the novel "The Gift of Maggie" [J]. Masterpieces, 2017 (4)

[13] Zou Xiangxi. Analysis of Chun Wang and its three English translations from the perspective of transitivity [J]. Overseas English, 2010 (9)

[14] Liu Xuewei. Analysis of the Transitivity of Obama's Graduation Ceremony [J]. Journal of Language and Literature Studies (Foreign Language Education and Teaching), 2014 (9)

[15] Zhang Delu. The development of systemic functional linguistics in China [J]. Foreign Language World, 2006 (2)

[16] Thompson, G. Introducing Functional Grammar [M]. London: Edward Arnold, 1996. 